Original Article

\title{
FORMULATION OF SOLID DISPERSIONS FOR ENHANCEMENT OF SOLUBILITY AND DISSOLUTION RATE OF SIMVASTATIN
}

\section{PAYAL D. BORAWAKE ${ }^{*}$, KAUSLYA ARUMUGAM ${ }^{1}$, JITENDRA V. SHINDE ${ }^{1}$}

\author{
1Department of Pharmaceutics, Pune District Education Association's, Seth Govind Raghunath Sable College of Pharmacy, Saswad, Pune, \\ Maharashtra, India \\ Email: borawake82@gmail.com
}

Received: 23 Feb 2021, Revised and Accepted: 29 May 2021

\begin{abstract}
Objective: The objective of the present work was to formulate the solid dispersions of simvastatin for enhancement of its aqueous solubility and dissolution rate.

Methods: In the present study, solid dispersions of simvastatin were prepared by Kneading and Solvent evaporation methods. The polymeric carriers like Polyethylene glycol (PEG) 6000 and Polyvinyl Pyrrolidone (PVP) K30 were used in different ratios (ratio of drug: carrier was 1:1, 1:2) to formulate solid dispersions. The prepared solid dispersions were characterized by differential scanning calorimetry (DSC), Fourier transforms infrared spectroscopy (FTIR), and evaluated for drug content, percentage yield, saturation solubility, in vitro dissolution studies. The best formula of
\end{abstract} the solid dispersion was selected according to the solubility and dissolution data.

Results: The F7 formulation was found to be an optimized formulation containing PVP K30 in the ratio 1:1 prepared by solvent evaporation technique. The Drug content was found to be higher i.e. 94.89 in the F7 batch. The FT-IR spectra revealed that there was no interaction between drugs and carriers. DSC thermogram indicated entrapment of simvastatin in PVP K30 and the conversion of crystalline simvastatin into an amorphous form. The F7 formulation showed maximum drug release i.e. $98.60 \%$ in 60 min which is 2 times greater than pure drug making it an optimized formulation.

Conclusion: The solubility of simvastatin was successfully enhanced through the solid dispersion technique. Solid dispersions prepared with solvent evaporation method were more soluble than solid dispersions prepared with kneading method with carrier PVP K30.

Keywords: Simvastatin, Polymeric carriers, Solid dispersion, Polyvinyl Pyrrolidone K30, Solvent evaporation method, Solubility enhancement

(C) 2021 The Authors. Published by Innovare Academic Sciences Pvt Ltd. This is an open access article under the CC BY license (https://creativecommons.org/licenses/by/4.0/) DOI: https://dx.doi.org/10.22159/ijpps.2021v13i7.41205. Journal homepage: https://innovareacademics.in/journals/index.php/ijpps.

\section{INTRODUCTION}

Near about $35-40 \%$ of new chemical entities possess the problem of low aqueous solubility that affects drug absorption in the gastrointestinal tract (GIT) which leads to lower bioavailability, high inter and intrasubject variability, dose dumping chances, reduction in the effectiveness of the medication, and lastly, formulation development get collapsed [1]. In such cases, scientists look for better formulations that will improve solubility and thus dissolution and bioavailability get improved. Various strategies involved are micronization, salt formation, solubilization, self-micro emulsifying drug delivery system, complexation, prodrug approaches, dendrimers formation, spray drying, solid solution/solid dispersion with hydrophilic carriers, nano-particular systems [2].

According to the Biopharmaceutical Classification System (BCS), oral medications are classified into four classes based on their solubility and permeability characteristics. Out of the four classes, class II and class IV possess the problem of low aqueous solubility, so there is a need to improve solubility by using different solubility enhancement techniques to improve in vitro dissolution and bioavailability of medications [3]. Solid dispersion is gaining more focus in few decades. Solid dispersion is defined as a group of solid products consisting of at least two components, hydrophobic drug, and hydrophilic carrier. The term dispersion means a hydrophobic drug is dispersed in an inert hydrophilic matrix [4].

Simvastatin is a Cholesterol-lowering, hydrophobic drug having a $\log$ P value of 4 . It is a BCS Class II drug with low aqueous solubility $(30 \mu \mathrm{g} / \mathrm{ml})$. It is a white crystalline powder. It acts as a specific potent inhibitor of 3-hydroxy-3-methyl-glutaryl coenzyme A (HMG CoA) reductase which reduces HMG CoA to mevalonate thus blocking vital steps for cholesterol biosynthesis in the liver, so it is extensively employed in the treatment of hypercholesterolemia and dyslipidemia. The structure of simvastatin is shown in fig. $1[5,6]$

In the present research, trials were taken to improve the solubility and thus dissolution rate of simvastatin by formulating its solid dispersions. Different concentrations of carriers were used for preparing solid dispersions and prepared free-flowing dispersions then evaluated for Solubility, FT-IR, and DSC analysis.<smiles>CCC(C)(C)C(=O)O[C@H]1C[C@@H](C)C=C2C=C[C@H](C)[C@H](CC[C@@H]3C[C@@H](O)CC(=O)O3)[C@H]21</smiles>

Fig. 1: Structure of simvastatin

\section{MATERIALS AND METHODS}

\section{Materials}

Simvastatin gift sample was obtained from Cipla Pvt. Ltd. (Mumbai). Polyvinyl pyrrolidone K30 has been purchased from Loba Chemie Pvt. Ltd. Mumbai. Polyethylene glycol 6000, Ethanol was obtained from Research Lab Fine Chemical Industries Pvt. Ltd. (Mumbai). Other chemicals and reagents were of analytical grade. 


\section{Methods}

\section{Physicochemical characterization of drug}

The Drug was identified by various physicochemical properties such as Color, Odour, Melting point, DSC analysis, and FT-IR spectroscopy [7].

\section{Determination of saturation solubility of simvastatin}

Solubility of simvastatin was determined by the shake flask method in different solvents like water, ethanol, methanol, chloroform, phosphate buffer $\mathrm{pH}$ 6.8, and phosphate buffer $\mathrm{pH}$ 7.4. Saturated solutions of simvastatin were prepared in different solvents and were stirred for $24 \mathrm{~h}$ using a rotary shaker. The solution was then filtered through Whatmann filter paper. The concentration of simvastatin was determined using a UV spectrophotometer against the respective solvent as blank at $\lambda$ max of drug [8].

\section{Preparation of calibration curve in ethanol}

The stock solution was prepared by taking accurately weighed 100 $\mathrm{mg}$ of simvastatin in a $100 \mathrm{ml}$ volumetric flask and dissolving it in ethanol and volume made up to the $100 \mathrm{ml}$ mark. The concentration of the solution was $1000 \mu \mathrm{g} / \mathrm{ml}$. From the stock solution, $1 \mathrm{ml}$ was pipetted in a $10 \mathrm{ml}$ volumetric flask and the volume was made up to mark with distilled water to obtain the concentration of $100 \mu \mathrm{g} / \mathrm{ml}$. This was a working standard solution. from this solution, $0.5,1,1.5$, $2,2.5$ and $3 \mathrm{ml}$ were pipetted in separate $10 \mathrm{ml}$ volumetric flasks and diluted up to mark with distilled water to get final concentrations of $5,10,15,20,25,30 \mu \mathrm{g} / \mathrm{ml}$. The Samples were measured spectrophotometrically at $\lambda$ max of a drug against ethanol as a blank. Absorbance values were plotted against concentrations of the drug to obtain a calibration curve [9].

\section{Preparation of solid dispersions (SDs)}

Solid dispersions of simvastatin were prepared using kneading and solvent evaporation methods employing PEG 6000 and PVP K30 as carriers. Prepared solid dispersions (SDs) were compared with pure drug and physical mixtures of drug and polymer.

\section{Physical mixture}

Simvastatin and carriers (PEG 6000, PVP K30) were mixed in mortar and pestle to obtain physical mixtures.

\section{Kneading method}

Drug and carriers (PEG 6000 and PVP K30) were mixed in different ratios i.e. 1:1, 1:2. A small amount of solvent (ethanol) was added into the mixture of drug and carrier until the formation of paste. Then that obtained paste was kneaded for few minutes and dried in an oven at $40{ }^{\circ} \mathrm{C}$. The dried mass was then ground and sieved through sieve No. 80. The formulations were encoded as F1, F2, F3, and F4. F1 and F2 for PEG SDs and later for PVP SDs [10].

\section{Solvent evaporation method}

Solid dispersions of simvastatin in PEG 6000 and PVP K30 prepared by solvent evaporation method with ratios $1: 1$ and 1:2 were denoted by F5, F6, F7, and F8 respectively. The required amount of carrier dissolved in a sufficient quantity of ethanol. To this, the solution of the drug was added with continuous stirring until the formation of a clear solution. The solvent then evaporated leaving behind solidified mass. The mass was dried, grounded, and sifted through sieve No. 80. The prepared dispersions were then characterized [11].

\section{Characterization of solid dispersions}

\section{Saturation solubility determination}

The Shake flask method was used for the determination of the solubility of prepared solid dispersions. The excessive quantity of prepared SDs was added in a glass stoppered flask containing $25 \mathrm{ml}$ of solvent and flasks were shaken for $24 \mathrm{~h}$ at $37 \pm 0.5{ }^{\circ} \mathrm{C}$. After $24 \mathrm{~h}$, the solution was filtered, diluted appropriately and absorbance was taken at the $\lambda$ max of a drug. Analysis of each sample was carried out in triplicate. The Change in solubility value was compared with pure drug solubility.

\section{Determination of percentage yield}

The Percentage yield of F1 to F8 formulations was calculated by using the following equation [12]. Determination was carried out in triplicate

$$
\% \text { yield }=\frac{\text { Actual weight of solid dispersion }}{\text { Total weight of } \mathrm{drug} \text { and carrier }} \times 100
$$

\section{Estimation of drug content}

The Solid dispersion equivalent to $10 \mathrm{mg}$ of drug was dissolved in 10 $\mathrm{ml}$ of ethanol, filtered, diluted, and drug content was determined using UV spectrophotometer at $\lambda$ max of a drug against ethanol as a blank. Analysis of each sample was carried out in triplicate [13].

\section{Fourier transform infrared spectroscopy}

By using FT-IR Spectrophotometer (FT-IR 8400S, Shimadzu), compatibility studies of drugs and carriers were carried out. FTIR spectra of SDs and physical mixture were obtained by the potassium bromide method in which powder is scanned in the range of 4000 $400 \mathrm{~cm}^{-1}$ with resolution $1 \mathrm{~cm}^{-1}$ [14]

\section{DSC analysis}

DSC thermographs of the physical mixture, solid dispersion were obtained using the Mettler-Toledo instrument. Samples were sealed in pierced aluminum pans and heated to a scanning rate of 10 ${ }^{\circ} \mathrm{C} / \mathrm{min}$ over the temperature range of $40-350{ }^{\circ} \mathrm{C}$. The inert atmosphere in the chamber was maintained by providing nitrogen gas at a flow rate of $40 \mathrm{ml} / \mathrm{min}$ [15].

\section{In vitro dissolution studies}

The in vitro Dissolution data was obtained by using USP Type II (Paddle type) dissolution apparatus with a rotating speed of 100 rpm and the media used was $900 \mathrm{ml}$ phosphate buffer $\mathrm{pH} 6.8$ maintained at $37 \pm 0.5{ }^{\circ} \mathrm{C}$. Sample equivalent to $40 \mathrm{mg}$ added in dissolution media. At specific time intervals i.e. after every $10 \mathrm{~min}$, a $5 \mathrm{ml}$ sample was pipetted, and an equal amount of fresh media was added. Pipetted samples were filtered, diluted, and analyzed by UV spectrophotometer at $\lambda \max$ of drug [16]. Analysis of each sample was carried out in triplicate.

\section{RESULTS AND DISCUSSION}

The Drug was found to be in solid, off-white powdered form. The melting point was determined by the capillary method and it was found to be in the range of $138-140{ }^{\circ} \mathrm{C}$ which is the same as the standard reported melting point [17].

Being a class II drug, simvastatin having low aqueous solubility. Solubility was found to be $0.028 \mathrm{mg} / \mathrm{ml}$ in distilled water, 0.125 $\mathrm{mg} / \mathrm{ml}$ in ethanol, $0.118 \mathrm{mg} / \mathrm{ml}$ in methanol, $0.619 \mathrm{mg} / \mathrm{ml}$ in chloroform, $2.418 \mathrm{mg} / \mathrm{ml}$ in phosphate buffer 6.8 and $0.865 \mathrm{mg} / \mathrm{ml}$ in phosphate buffer 7.4.

The calibration curve was done by using a UV-spectrophotometer. Absorbance maxima ( $\lambda \max$ ) was found to be at $238 \mathrm{~nm}$, so the calibration curve was prepared in ethanol at $238 \mathrm{~nm}$. [18]. The plot had a correlation coefficient $\left(\mathrm{R}^{2}\right)$ of 0.996 , a slope of 0.022 , and a Cintercept of-0.012. These results indicated that there is a linear relationship between concentration $(5-25 \mu \mathrm{g} / \mathrm{ml})$ and absorbance, as shown in fig. 2 . As per the literature survey, it is confirmed that simvastatin show linearity in the concentration range of 5 to 30 $\mu \mathrm{g} / \mathrm{ml}$ when ethanol is used as a solvent and also as a blank.

The Solubility of solid dispersions was determined and compared with that of pure drug solubility in distilled water. It was found to be an increase in solubility of all the prepared solid dispersions as shown in table 1 . The maximum increase in solubility was found in the F7 formulation that was prepared by solvent evaporation technique employing PVP k30 as a carrier in the ratio of 1:1 with the drug. So, here it can be said that PVP k30 is the more effective carrier in preparing SDs than PEG 6000. Literature also supports the enhancement of solubility of solid dispersions is better with the hydrophilic carrier PVP K30 than the PEGs by the solvent method. This improved solubility can be attributed to the solubilization effect of the carrier, which increases the wetting property of the drug [14]. 


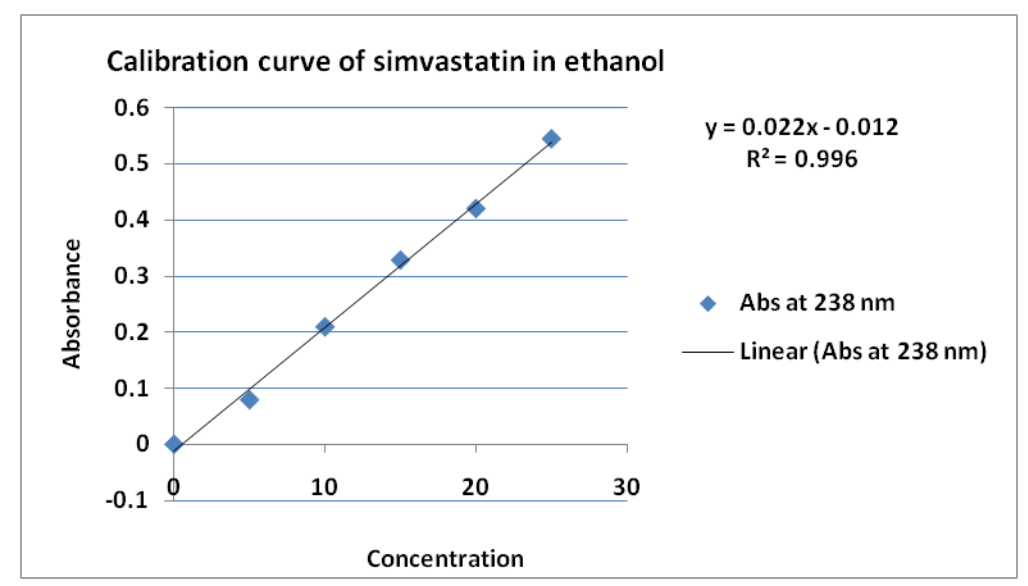

Fig. 2: Calibration curve of simvastatin

Table 1: Solubility data of pure drug and prepared solid dispersions

\begin{tabular}{ll}
\hline Formulation code & $*$ Solubility $(\mathbf{m g} / \mathbf{m l})$ \\
\hline Pure drug & $0.028 \pm 0.20$ \\
F1 & $0.814 \pm 0.19$ \\
F2 & $1.643 \pm 0.32$ \\
F3 & $3.651 \pm 0.18$ \\
F4 & $5.815 \pm 0.65$ \\
F5 & $3.246 \pm 0.45$ \\
F6 & $4.974 \pm 0.22$ \\
F7 & $8.982 \pm 0.51$ \\
F8 & $7.489 \pm 0.21$ \\
\hline
\end{tabular}

*Data expressed as mean \pm standard deviation (SD), $\mathrm{n}=3$

The percentage yield and drug content for different ratios of drug and carrier were calculated by using formula and values are shown in table 2 . The percentage yield values were found to get decreased at the higher ratios of the carrier due to the difficulty during sieving. Drug content values are found to in the range of 88.75 to $94.89 \%$.
Low standard deviation between values indicated uniformity of drug content in all formulations [19]. In Percentage yield values, the yield was high in the F3 batch i.e. $95.23 \%$ but drug content was $90.26 \%$. In F7 formulation, though the yield is $93.18 \%$, actual drug content was found to be higher i.e. 94.89 .

Table 2: Percentage yield and drug content of prepared solid dispersions

\begin{tabular}{lll}
\hline Formulation code & *Percentage yield & $*$ Drug content \\
\hline F1 & $92.11 \pm 0.961$ & $89.22 \pm 0.003$ \\
F2 & $92.87 \pm 1.023$ & $88.75 \pm 0.017$ \\
F3 & $95.23 \pm 1.104$ & $90.26 \pm 0.012$ \\
F4 & $89.08 \pm 0.025$ & $93.83 \pm 0.007$ \\
F5 & $92.01 \pm 0.725$ & $90.81 \pm 0.013$ \\
F6 & $90.27 \pm 1.621$ & $92.48 \pm 0.003$ \\
F7 & $93.18 \pm 1.321$ & $94.89 \pm 0.002$ \\
F8 & $91.09 \pm 0.984$ & $93.14 \pm 0.006$ \\
\hline
\end{tabular}

*Data expressed as mean \pm standard deviation (SD), $\mathrm{n}=3$

FT-IR spectrum of simvastatin showed peaks of characteristic functional groups at wavenumbers $3549.14 \mathrm{~cm}^{-1}$ (free O-H stretching vibrations), $1705 \mathrm{~cm}-1$ (stretching vibration of ester and lactone carbonyl functional groups), and $2877 \mathrm{~cm}^{-1}, 2955 \mathrm{~cm}^{-1}$ (C-H stretching vibrations) as shown in fig 3. FT-IR spectrum of PVP K30 is shown in fig. 4 . The major peaks of simvastatin were retained in the physical mixture and solid dispersions as shown in fig. 5 and fig. 6, respectively. Peaks of-OH Stretch (3566.85 $\mathrm{cm}^{-1}$ ), carbonyl group (1697.47) are observed to be shifted by some difference. The possible reason for shifting is intermolecular hydrogen bonding. But, no major difference was observed which indicates the compatibility of drug and PVP K30 in solid dispersion. In Solid dispersions, the possibility of hydrogen bonding between simvastatin and PVP is due to PVP. As PVP has two groups $=\mathrm{N},=0$ that can potentially form a hydrogen bond with the drug [15].
The DSC Thermogram of simvastatin showed a sharp endothermic peak at $140{ }^{\circ} \mathrm{C}$ temperature as shown in fig. 7. The sharp, intense peak indicates the pure crystalline nature of the drug. PVP K30 showed a wide endotherm in the temperature range of $56-95{ }^{\circ} \mathrm{C}$ which can be attributed to loss of water due to hygroscopic nature [20]. In the physical mixture, both endotherms were observed indicating compatibility of drug and PVP K30. Lastly, in SD Thermogram, a less sharp peak of the drug was seen or can be said to be disappeared as compared to the thermogram of pure drug, but a wide endotherm at the range of $50-95{ }^{\circ} \mathrm{C}$ indicates entrapping of simvastatin in the carrier and confirms the amorphous nature of solid dispersion. A decrease in the intensity of the sharp peak of simvastatin can be attributed to increased dissolution or entrapment of simvastatin in the PVP K30 [21]. 


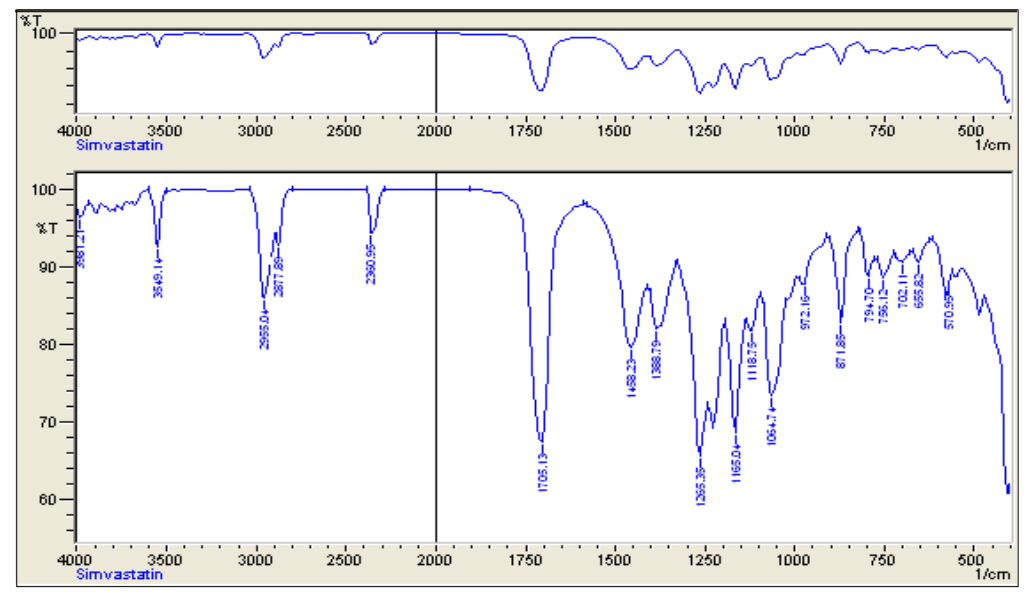

Fig. 3: FTIR spectrum of simvastatin

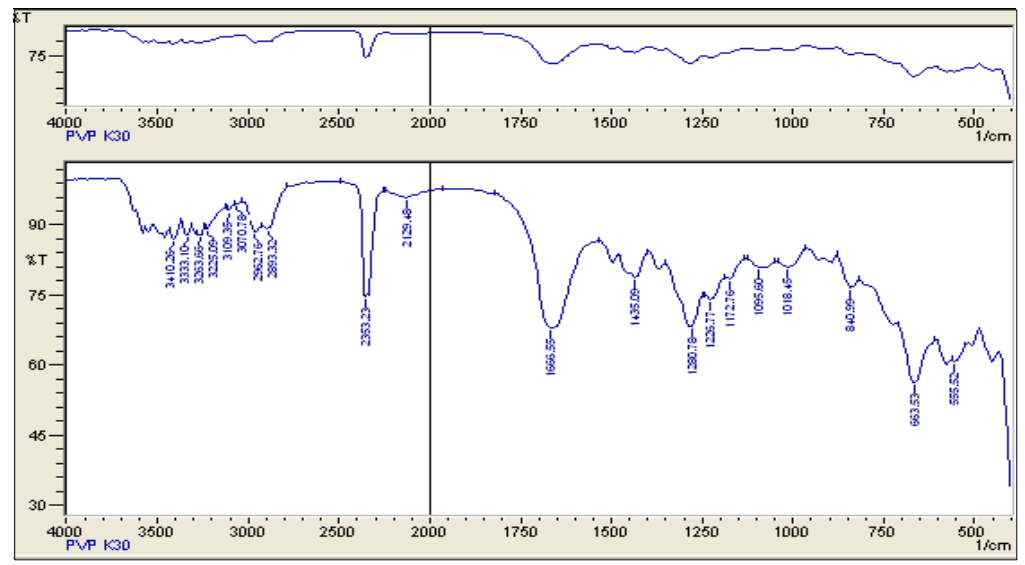

Fig. 4: FTIR spectrum of PVP K30

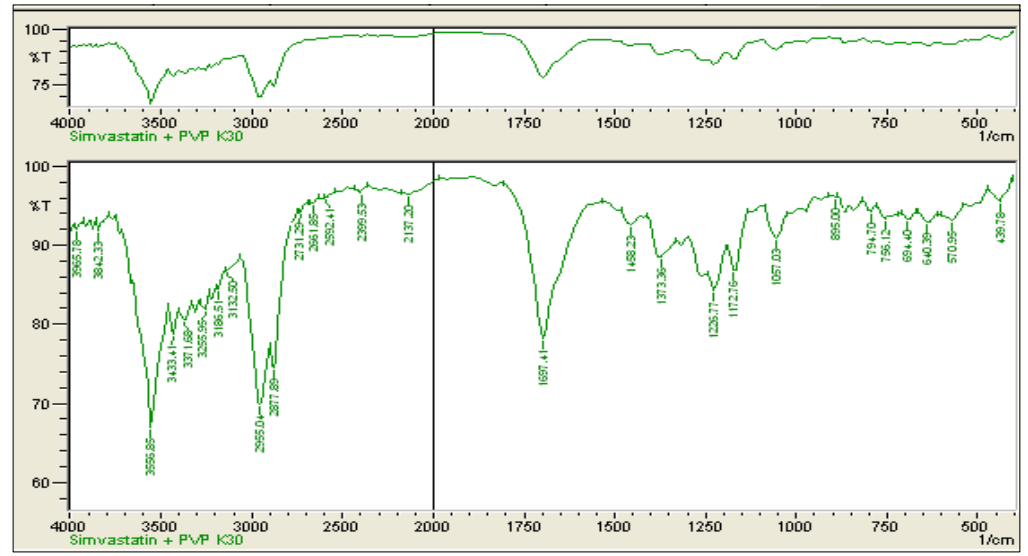

Fig. 5: FTIR spectrum of physical mixture of simvastatin and PVP K 30

The In vitro dissolution studies of pure drug, physical mixture, and SDs were carried out in phosphate buffer pH 6.8 up to 60 min. The pure drug showed $48.41 \%$ drug release in $60 \mathrm{~min}$ which indicates a poor dissolution profile. The formulations F1 to F4 which were prepared by the kneading method showed drug release from 84.73 to $93.20 \%$ in 60 min which indicated enhanced dissolution profile as compared to pure drug. The formulations F5 to F8 showed drug release from 94.72 to
$98.60 \%$ drug release. F7 formulation showed maximum drug release i.e. $98.60 \%$ in 60 min which is 2 times greater than pure drug. This marked increase in dissolution and solubility can be attributed to the reduced, uniform particle size and hydrophilic nature of PVP K30. Thus from the above data, it can be said that simvastatin PVP SDs show better dissolution profiles compared to that of PEG 6000 , even at the lowest PVP ratio i.e. (1:1) by solvent evaporation method [22]. 


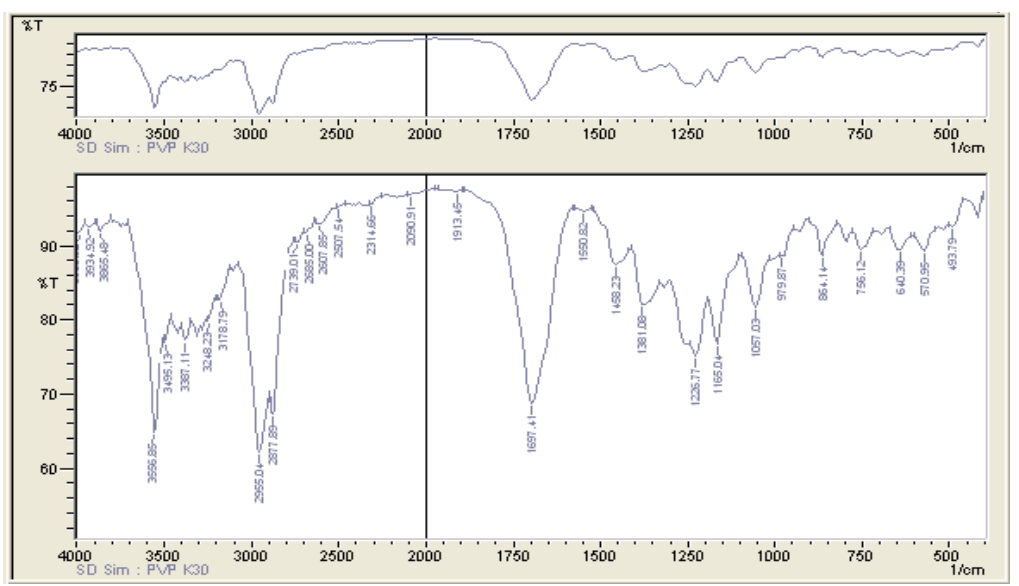

Fig. 6: FTIR spectrum of solid dispersion of simvastatin and PVP K30 (F7 formulation)

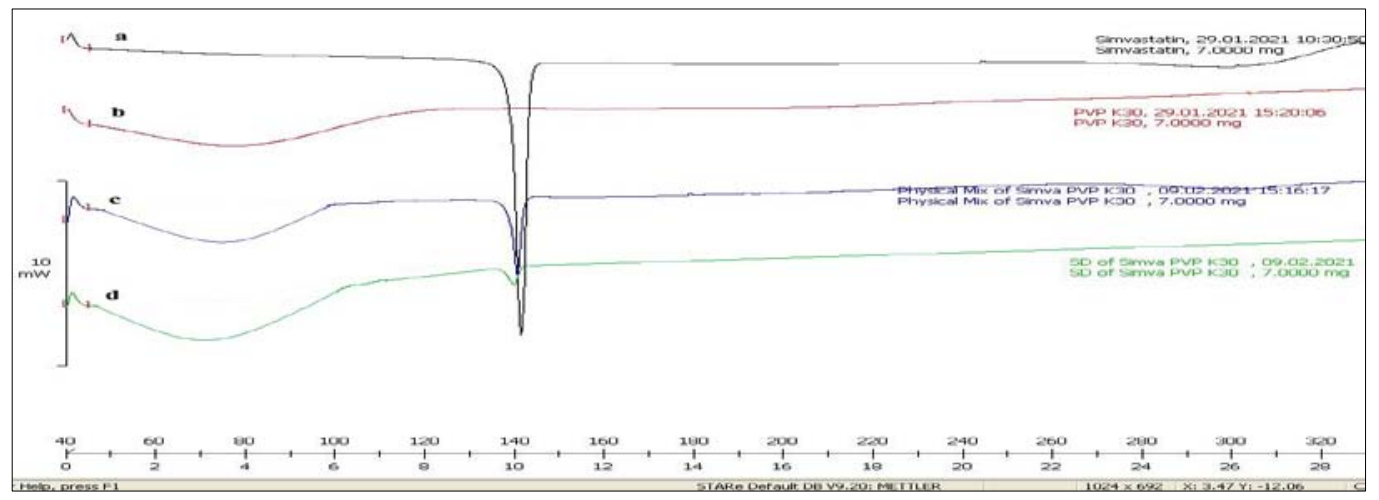

Fig. 7: Overlay of DSC thermograms of (a) Simvastatin, (b) PVP K30, (c) Physical mixture of simvastatin and PVP K30, (d) Solid dispersion of simvastatin and PVP K30 (1:1)

Table 3: Dissolution data of prepared solid dispersions

\begin{tabular}{|c|c|c|c|c|c|c|c|c|c|}
\hline \multirow{2}{*}{$\begin{array}{l}\text { Time } \\
\text { (in min) }\end{array}$} & \multicolumn{9}{|c|}{ *Percentage (\%) drug release } \\
\hline & Drug & F1 & F2 & F3 & F4 & F5 & F6 & F7 & F8 \\
\hline 0 & $1.088 \pm 1$ & $1.914 \pm 1$ & $1.783 \pm 2$ & $2.871 \pm 1$ & $3.362 \pm 1$ & $1.726 \pm 1$ & $1.669 \pm 2$ & $8.762 \pm 1$ & $7.862 \pm 1$ \\
\hline 5 & $2.299 \pm 1$ & $3.051 \pm 2$ & $3.984 \pm 1$ & $8.181 \pm 2$ & $9.981 \pm 2$ & $6.676 \pm 2$ & $6.520 \pm 1$ & $20.23 \pm 1$ & $16.38 \pm 1$ \\
\hline 10 & $3.878 \pm 1$ & $6.054 \pm 1$ & $9.154 \pm 1$ & $16.99 \pm 1$ & $21.11 \pm 1$ & $18.42 \pm 1$ & $19.05 \pm 2$ & $31.83 \pm 2$ & $27.58 \pm 2$ \\
\hline 20 & $7.601 \pm 2$ & $14.90 \pm 2$ & $21.53 \pm 2$ & $30.83 \pm 1$ & $33.40 \pm 2$ & $31.27 \pm 1$ & $34.48 \pm 1$ & $43.88 \pm 2$ & $39.94 \pm 2 \pm$ \\
\hline 30 & $16.16 \pm 2$ & $30.39 \pm 2$ & $36.85 \pm 2$ & $48.16 \pm 2$ & $47.06 \pm 2$ & $44.51 \pm 2$ & $50.61 \pm 2$ & $56.46 \pm 2$ & $52.60 \pm 1$ \\
\hline 40 & $26.60 \pm 1$ & $46.21 \pm 2$ & $51.00 \pm 1$ & $67.27 \pm 2$ & $64.33 \pm 3$ & $60.09 \pm 2$ & $68.27 \pm 1$ & $69.56 \pm 2$ & $66.62 \pm 1$ \\
\hline 50 & $37.35 \pm 1$ & $65.13 \pm 2$ & $67.97 \pm 1$ & $87.04 \pm 2$ & $82.97 \pm 2$ & $77.17 \pm 2$ & $86.71 \pm 2$ & $86.48 \pm 1$ & $80.91 \pm 2$ \\
\hline 60 & $48.41 \pm 1$ & $84.73 \pm 1$ & $86.43 \pm 1$ & $90.69 \pm 1$ & $93.20 \pm 2$ & $95.81 \pm 1$ & $94.72 \pm 1$ & $98.60 \pm 1$ & $96.48 \pm 1$ \\
\hline
\end{tabular}

*Data expressed as mean \pm standard deviation (SD), $\mathrm{n}=3$

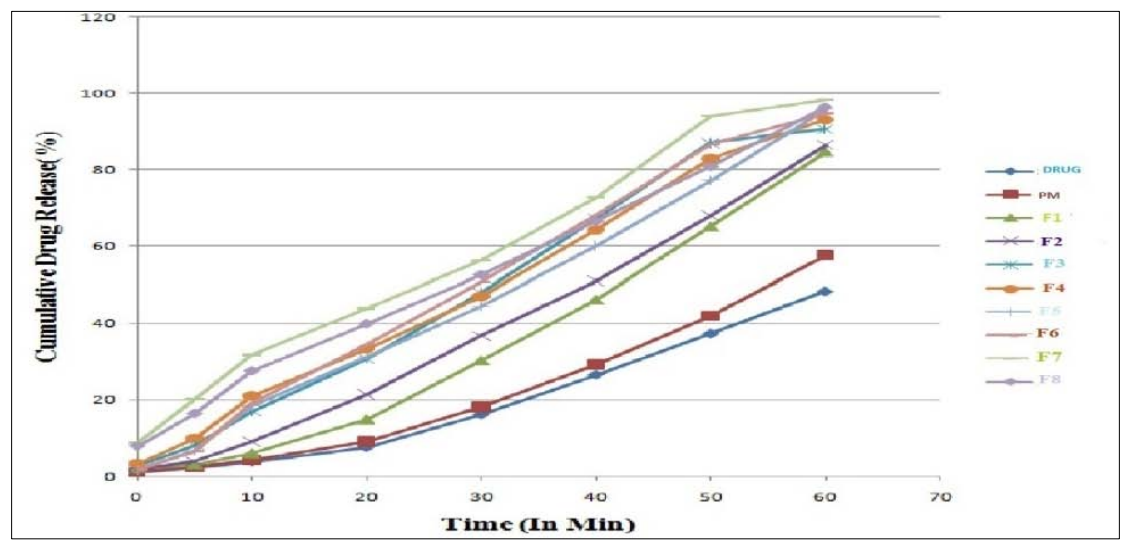

Fig. 8: In vitro dissolution profile of a pure drug, physical mixture, and solid dispersions (F1 to F8) 
The in vitro dissolution data is given in table 3. By using Dissolution data, a graph is plotted between Cumulative \% drug release and time which is shown in fig. 8. As per solubility and dissolution data, it can be confirmed that solvent evaporation is the best method as compared to kneading and the physical mixture method for the preparation of solid dispersions. In fig. 9, dissolution profiles of pure drug, physical mixture, F3, and F7 formulations are shown which indicates enhancement of simvastatin dissolution rate by a solvent evaporation method (F7 formulation dissolution profile). In the literature review of cefixime solid dispersions, the maximum increase in the dissolution rate was obtained with the dispersions prepared through the solvent evaporation method than the kneading method, and comparatively faster dissolution rates were obtained than that of the pure drug [23].

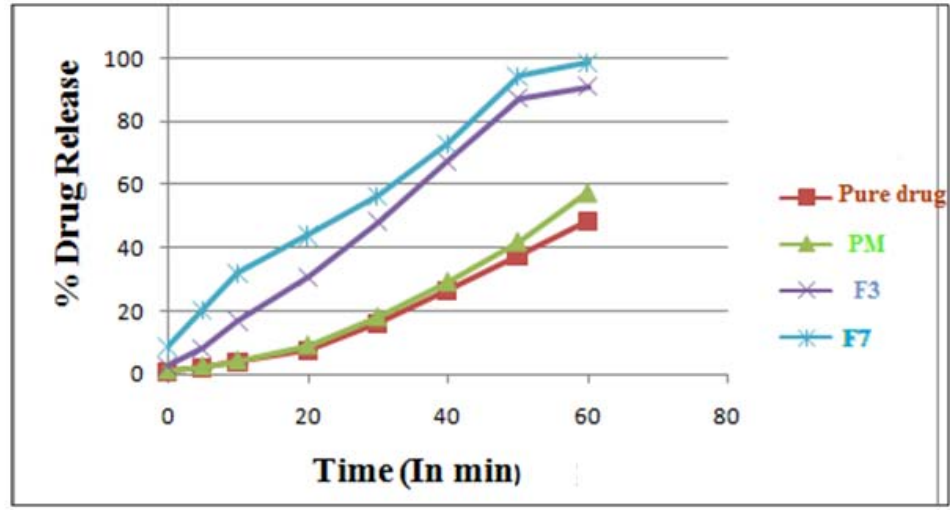

Fig. 9: In vitro dissolution profile of a pure drug, physical mixture, F3 and F7 formulation

F7 was found to be the best formulation so drug release kinetics was obtained from in vitro dissolution data and shown in table 4 . It was found to follow a zero-order kinetic model with an $\mathrm{R}^{2}$ of 0.986 as shown in fig. 10 .

Table 4: Correlation coefficient values for optimized formulation

\begin{tabular}{lllll}
\hline $\begin{array}{l}\text { Formulation } \\
\text { code }\end{array}$ & \multicolumn{2}{l}{ Correlation coefficient $\left(\mathbf{r}^{2}\right)$ values } & \\
\cline { 2 - 5 } & Zero order model & Korsemeyer peppas model & Higuchi model & Hixson crowell model \\
\hline F7 & 0.986 & 0.982 & 0.970 & 0.965 \\
\hline
\end{tabular}

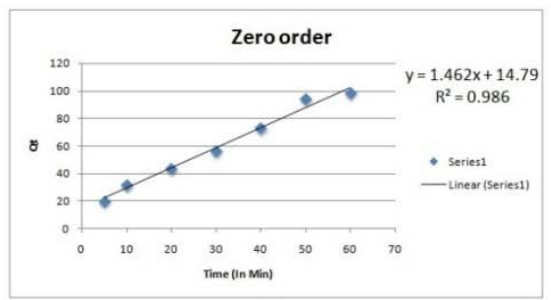

(a)

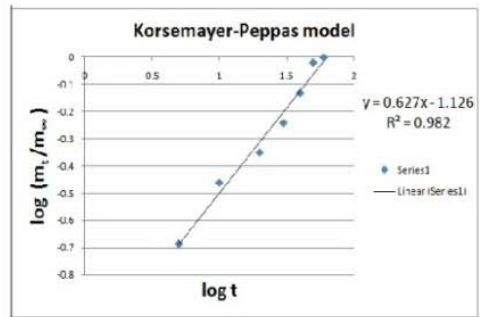

(b)

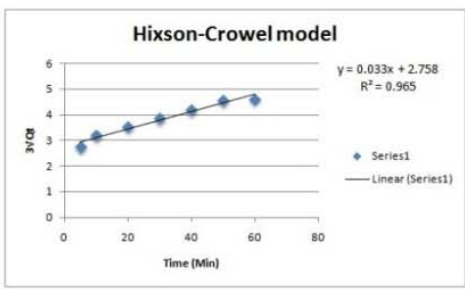

(d)

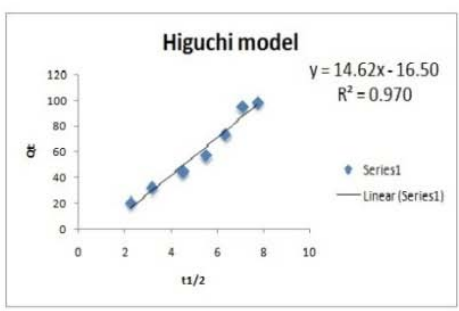

(c)

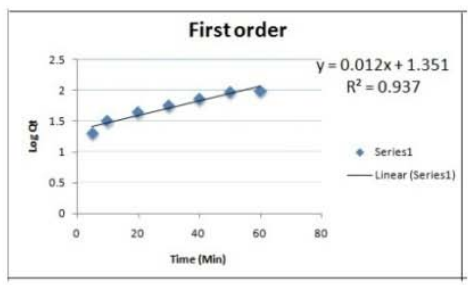

(e)

Fig. 10: Dissolution release kinetics (a) Zero-order model, (b) Korsemeyer peppas plot, (c) Higuchi model, (d) Hixson crowell model, (e) First order model 


\section{CONCLUSION}

The solid dispersions of simvastatin prepared by kneading and solvent evaporation method with two different carriers (PEG 6000, PVP K30) showed considerably higher drug dissolution in comparison with pure drug. The result showed that the solid dispersions prepared with the solvent evaporation method give a higher dissolution rate than the kneading method. Amongst the carrier used, PVP K30 showed significant enhancement in solubility and dissolution. SD of drug and PVP K30 in the ratio of 1:1 gave a higher intrinsic dissolution rate. The DSC Thermogram of optimized solid dispersion batch (F7) showed entrapment of drug in a carrier matrix and confirmed amorphous nature. PVP K30 does not show any incompatibility with simvastatin and that was confirmed by FTIR analysis. Thus, the present research concluded that solid dispersion technology can be used effectively to enhance the solubility and also dissolution rate of the poorly water-soluble drug simvastatin.

\section{FUNDING}

This study was not funded.

\section{AUTHORS CONTRIBUTIONS}

All authors in the present research study have contributed their equal parts. Payal D. Borawake has collected the data, designed the study, and performed the experimental work. Kauslya Arumugam has interpreted the data. The research was guided and supervised by Jitendra V. Shinde. All authors contributed to the manuscript writing.

\section{CONFLICT OF INTERESTS}

None

\section{REFERENCES}

1. Saffoon N, Uddin R, Huda NH, Sutradhar KB. Enhancement of oral bioavailability and solid dispersion: a review. J Appl Pharm Sci 2011;1:13-20.

2. Pawar SR, Barhate SD. Solubility enhancement (Solid Dispersions) novel boon to increase bioavailability. J Drug Delivery Ther 2019;9:583-90.

3. Gurunath S, Kumar SP, Basavaraj NK, Patil PA. Amorphous solid dispersion method for improving oral bioavailability of poorly water-soluble drugs. J Pharm Res 2013;6:476-80.

4. Mir KB, Khan NA. Solid dispersion: overview of the technology. Int J Pharm Sci Res 2017;8:2378-87.

5. Komal, Kaur T, Singh AP, Singh AP, Sharma P. Enhancement of solubility and dissolution rate of simvastatin by using solid dispersion technique along with different combination of polymers. J Drug Delivery Ther 2018;8:32-40.

6. Pabari RM, Jamil A, Kelly JG, Ramtoola Z. Fast disintegrating crystalline solid dispersions of simvastatin for incorporation into orodispersible tablets. Int J Pharm Invest 2014;4:51-9.

7. Pawar CV, Mutha SS, Bhise SV, Borawake PD. Formulation and evaluation of mouth dissolving tablet of meloxicam using natural superdisintegrants. Asian J Pharm Clin Res 2020;13:197-203.

8. Shinde AJ, Dalavi RS, More HN. Design and development of melt solidification of meloxicam for enhancement of solubility and dissolution. J Res Pharm 2020;24:56-70.

9. More AS, Firake BM, Firke SD. Spectrophotometric methods for estimation of simvastatin in bulk drug and its dosage form. Anal Chem Indian J 2016;16:258-64.

10. Shaik M. Formulation and evaluation of solid dispersions of carbamazepine using various carriers by physical mixing and kneading method (KM). Int J Trends Pharm Life Sci 2016;2:945-55.

11. Raj AL, Kumar SY. Preparation and evaluation of solid dispersion of nebivolol using the solvent evaporation method. Int J Pharm Sci Drug Res 2018;10:322-8.

12. Aleti SR, Rangaraju D, Kant A, Shankraiah MM, Venkatesh JS, Rao RN, et al. Solubility and dissolution enhancement of cefixime using natural polymer by solid dispersion technique. Int J Res Pharm Chem 2011;1:283-8.

13. Bolla N, Chandra S, Raju CHR, Rao GSNK, Devi PU. Improvement of simvastatin solubility using natural polymers by solid dispersion technique. Int J Pharm Res Biomed Anal 2013;2:1-6.

14. Sapkal SB, Adhao VS, Thenge RR, Darakhe RA, Shinde SA, Shrikhande VN. Formulation and characterization of solid dispersions of etoricoxib using natural polymers. Turk J Pharm Sci 2020;17:7-19.

15. Shinde SS, Shete AS, Patil MV, Varne BS. Different binary polymer mixture for solubility enhancement of poorly watersoluble drug by solid dispersion technique. Int J PharmTech Res 2012;4:1159-66.

16. Bhagat SA, Sakhare AV. Formulation and evaluation of simvastatin solid dispersion tablets. Int J Sci Res 2014;3:1050-7.

17. Rao M, Mandage Y, Thanki K, Bhise S. Dissolution improvement of simvastatin by surface solid dispersion technology. Dissolution Technol 2010;2:27-34.

18. Birari AE. Development and validation of UV spectrophotometric method for estimation of simvastatin in bulk and solid dosage form. Int J Pharm Sci Res 2015;6:185-9.

19. Shah I, Bhatt S, Yadav A. Enhancement of solubility and dissolution of nebivolol by solid dispersion technique. Int J Pharm Pharm Sci 2014;6:566-71.

20. Frizon F, Oliveria EJ, Donaduzzi CM. Dissolution rate enhancement of lorantidine polyvinylpyrrolidone K-30 solid dispersions by solvent methods. Powder Technol 2013;235:532-9.

21. Kanaze F, Kokkalou E, Niopas I. Dissolution enhancement of flavonoids by solid dispersion in PVP and PEG matrixes: a comparative study. J Appl Polym Sci 2006;102:460-71.

22. Klecia MDS, Raquel MB, Fernanda GAV, Eduardo PA, Antonio CSL, Celso AC, et al. Development of solid dispersions of $\beta$ lapachone in PEG and PVP by the solvent evaporation method. Drug Dev Ind Pharm 2018;44:750-6.

23. Aleti SR, Rangaraju D, Kant A, Shankraiah MM, Venkatesh JS, Rao RN, et al. solubility and dissolution enhancement of cefixime using natural polymer by solid dispersion technique. Int J Res Pharm Chem 2011;1:283-8. 